\title{
Risk factors associated with 31-day unplanned readmission in 50,912 discharged patients after stroke in China
}

\author{
Tiancai Wen ${ }^{1,2,{ }^{\dagger}}$, Baoyan Liu ${ }^{3 \dagger}$, Xia Wan ${ }^{4}$, Xiaoping Zhang ${ }^{3}$, Jin Zhang ${ }^{3}$, Xuezhong Zhou ${ }^{5}$, Alexander Y. L. Lau ${ }^{6}$ \\ and Yanning Zhang ${ }^{1 *}$
}

\begin{abstract}
Background: Unplanned readmission within 31 days of discharge after stroke is a useful indicator for monitoring quality of hospital care. We evaluated the risk factors associated with 31-day unplanned readmission of stroke patients in China.

Methods: We identified 50,912 patients from 375 hospitals in 29 provinces, municipalities or autonomous districts across China who experienced an unplanned readmission after stroke between 2015 and 2016, and extracted data from the inpatients' cover sheet data from the Medical Record Monitoring Database. Patients were grouped into readmission within 31 days or beyond for analysis. Chi-squared test was used to analyze demographic information, health system and clinical process-related factors according to the data type. Multilevel logistic modeling was used to examine the effects of patient (level 1) and hospital (level 2) characteristics on an unplanned readmission $\leq 31$ days.

Results: Among 50,912 patients, 14,664 (28.8\%) were readmitted within 31 days after discharge. The commonest cause of readmissions were recurrent stroke (34.8\%), hypertension (22.94\%), cardio/cerebrovascular disease (13.26\%) and diabetes/ diabetic complications (7.34\%). Higher risks of unplanned readmissions were associated with diabetes $(\mathrm{OR}=1.089$, $P=0.001)$, use of clinical pathways $(\mathrm{OR}=1.174, P<0.001)$, and being discharged without doctor's advice $(\mathrm{OR}=1.485$, $P<0.001$ ). Lower risks were associated with basic medical insurances ( $O R$ ranging from 0.225 to $0.716, P<0.001$ ) and commercial medical insurance $(\mathrm{OR}=0.636, P=0.021)$, compared to self-paying for medical services. And patients aged 50 years old and above (OR ranging from 0.650 to $0.985, P<0.05)$, with haemorrhagic stroke $(\mathrm{OR}=0.467, \mathrm{P}<0.001)$, with length of stay more than 7 days in hospital (OR ranging from 0.082 to $0.566, P<0.001$ ), also had lower risks.
\end{abstract}

Conclusions: Age, type of stroke, medical insurance status, type of discharge, use of clinical pathways, length of hospital stay and comorbidities were the most influential factors for readmission within 31 days.

Keywords: Stroke, Unplanned readmission, Hospitalization, Cover sheet of medical record, Risk factor

\section{Background}

Stroke is an important public health concern in China as the leading cause of morbidity and mortality [1]. In the Report on Cardiovascular Diseases in China (2017), it was estimated that approximately 13 million Chinese people had suffered a stroke [2]. The mortality rate of stroke in China has been estimated to be 4 to 5 -fold

\footnotetext{
* Correspondence: ynzhang@nwpu.edu.cn

†Tiancai Wen and Baoyan Liu contributed equally to this work.

'School of Computer Science, Northwestern Polytechnical University Xi'an,

Shangxi Province 710129, China

Full list of author information is available at the end of the article
}

greater than in western developed countries [3]. Meanwhile, stroke causes an enormous economic burden in China; the hospitalization expenses for intracranial hemorrhage and cerebral infarction have increased by approximately 19 and $25 \%$ annually since $2004[4,5]$.

Readmissions after hospitalization increases the burden on patients and is a waste of health resources [6]. Unplanned early readmission is a potentially useful indicator for monitoring the quality of hospital care [7]; The National Health Commission of China uses unplanned readmission within 31 days of discharge for the same disease as an indicator of the medical quality of hospitals [8],

(C) The Author(s). 2018 Open Access This article is distributed under the terms of the Creative Commons Attribution 4.0 International License (http://creativecommons.org/licenses/by/4.0/), which permits unrestricted use, distribution, and 
including stroke [9]. Unplanned readmission within 31 days of discharge among patients with stroke may reflect unresolved problems at discharge or a lack of effective outreach care after discharge [10]. It has been shown that the risk of readmission can be reduced by better care during the index hospitalization, improvements in discharge planning and follow-up care/ outreach health care, or better transitions between inpatient and outpatient healthcare teams [11]. In addition, patients with stroke who were readmitted within one month after discharge had a worse functional outcome or higher mortality and medical costs than those who were not readmitted [12-14]. Therefore, in order to prevent avoidable readmissions, it is important to identify risk factors associated with 31-day unplanned readmission in discharged patients after stroke.

The most common causes of readmission among patients with stroke include recurrent stroke, infections, and cardiac diseases [15]. In addition, social and financial factors may contribute to readmissions in patients discharged after stroke [16]. Although several clinical trials and observational studies have examined the causes of readmission within one month of discharge after stroke, the impact of social, financial, hospital or health system-related factors remain uncertain due to small sample sizes or limited patient cohorts [10, 17]. In China, the cover sheet is the first page of the medical record for each individual inpatient, which provides detailed information, including patient characteristics, all diagnoses, clinical treatments or procedures, social circumstances, financial status, hospital type, cost and type of payment $[18,19]$. For patients with consecutive medical records, information about their past histories and all treatments provided after stroke are also recorded and linked by an unique individual identifier [20].

The aim of this study was to determine the factors associated with 31-day unplanned readmission in patients discharged after stroke by extracting the data of the index hospitalization and subsequent readmission from a large database of the medical record cover sheet.

\section{Methods}

\section{Data source}

This study used data collected from the Cover Sheet of Stroke Inpatients' Medical Records from the Monitoring Database of National Key Traditional Chinese Medicine (TCM) Project, which includes data from more than 50 million cover sheets from 578 TCM hospitals or TCM departments in general hospitals across China from Jan 2015 to Dec 2016. Diagnosis of TCM means patients are diagnosed by TCM theory (syndrome differentiation) with whole body, pulse and tongue symptoms. Treatment of TCM means patients were treated by Chinese herb or acupuncture. Nowadays, combined diagnosis and treatment of TCM and Western Medicine (WM) are the most common strategy used in TCM hospitals or clinics. Therefore, in the TCM hospitals or TCM departments, patients are diagnosed by both WM and TCM theory, then based on the western stroke treatment, doctors may add Chinese herb or acupuncture, depending on the severity of stroke patients. And in the tertiary TCM hospital, department of internal neurology or stroke unit is used for stroke patients.

The criteria for data inclusion in this study were 1) patients aged between 18 and 100 years with a principal diagnosis of haemorrhagic stroke (ICD-10 code: I61) or ischemic stroke (ICD-10 code: I63) (forty-one patients coded I64 were not considered because of the small sample size.); 2) patients readmitted to any hospital after discharge due to a stroke-related condition. The first onset of stroke was taken as the index event and readmission as the endpoint event. We were unable to evaluate the outcomes of patients who did not return to a hospital; they may have fully recovered or they may have died. Therefore, patients without readmission information, or with planned readmission $\leq 31$ days, or readmitted not for a stroke-related condition (such as toxic effect of snake venom or foodborne Bacillus cereus intoxication) were excluded. In order to protect patients' privacy, all data were anonymized by removing sensitive personal information, and subjects were identified by a hospital number or a personal identification number managed by the database administrators.

\section{Study variables}

Before undertaking the data analysis, occupation and the level of hospital were re-classified: 'Manager and staff' referred to civil officers, specialized technicians, clerks and leaders of organizations; 'Self-employed' included freelancers. In China, the retirement age for females and males was 55 and 60 years old, respectively [21]; and most Chinese reported that they had no job after retirement, so those people aged 55 (for females) or 60 (for males) years old and above without any job were classified to the 'retiree' group. Primary and secondary hospitals were combined, so the level of hospital classified into 'tertiary hospital' and 'primary or secondary hospital'.

Data included basic hospital information (including the level of hospital and type of hospital), patient demographic information (including sex, age, principal discharge diagnosis, and comorbidities), health care services and clinical processes provided (including admission route, medical expense payment, and use of TCM diagnosis/treatment). Due to the large data set, a great number of comorbidities were identified from the database. Based on the literature review [22-24], we pre-specified ten comorbidities that were regarded as contributing diseases to stroke, namely, 
Patients with a principal diagnosis of $\mathrm{I} 61$

or I63, aged $18-100$ years $(N=71,686)$

Exclude duplicate patients $(\mathrm{N}=279)$

Exclude patients without readmission

records $(\mathrm{N}=16,528)$

Exclude patients with planned readmission

$\leq 31$ days $(\mathrm{N}=1,591)$

Exclude patients not readmitted for a

stroke-related condition $(\mathrm{N}=2,376)$

Finally include 50,912 stroke patients

Fig. 1 Flowchart for patient selection hypertension, diabetes, dyslipidemia, and heart disease (including coronary heart disease, angina pectoris, arrhythmia, heart failure, atrial fibrillation, and myocardial infarction).

\section{Statistical analysis}

The data analysis and map drawing were performed by using $\mathrm{R}$ (version 3.4.3). Potential risk factors for readmission were compared by univariable analysis between patients readmitted $\leq 31$ days and $>31$ days with the chi-squared test. The multilevel logistic modeling (MLM) ( $\mathrm{R}$ package, lme4 version 1.1-15) was used to examine the effect of patient (level 1) and hospital (level 2) characteristics on an unplanned readmission $\leq 31$ days. The variables with a $P$ value of $<0.1$ from the univariable analysis were entered into the MLM.

Two steps were conducted to build the MLM: (1) an empty model containing no independent variables was used to describe the variation between hospitals; (2) all patient and hospital-level variables were entered into a full model to study fixed effects. In the final model, $P$ values of $<0.05$ were considered significant. Adjusted odds ratios (OR) with 95\% confidence interval (CI) were calculated. The degree of

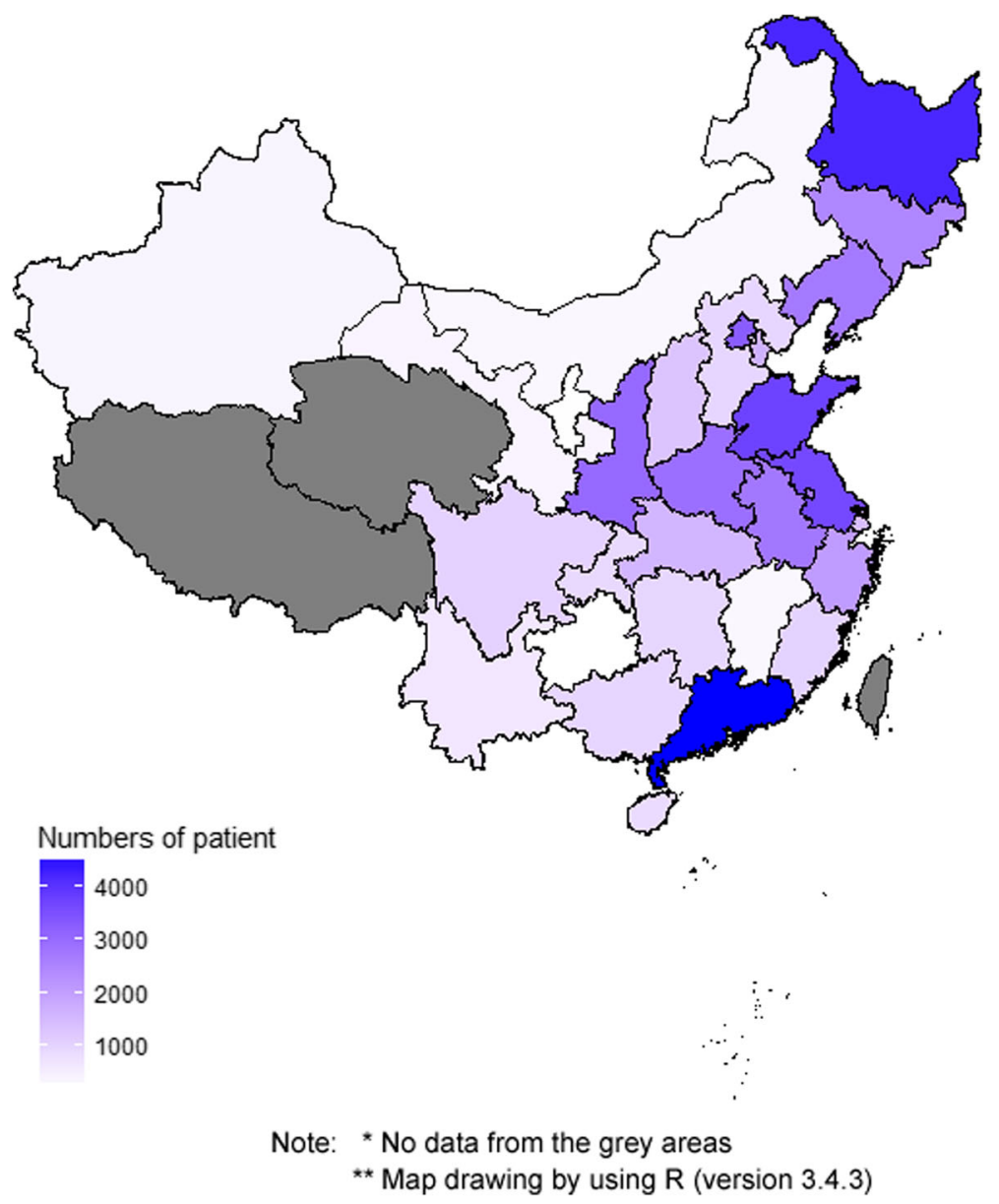

Fig. 2 The distribution of included patients across China. Number of patients 
heterogeneity of clinical services from the same hospital was computed using the interclass correlation.

\section{Results}

The results of the data inclusion procedure are shown in Fig. 1. A total of 50,912 eligible patients with stroke from 375 hospitals distributed among 29 provinces, municipalities or autonomous districts across China, who experienced an unplanned readmission after stroke from 2015 to 2016, were included in the study (Fig. 2).

Among all patients, $28.8 \%(14,664)$ were readmitted $\leq 31$ days after discharge. The reasons for readmissions are summarized in Fig. 3. The commonest causes were recurrent stroke, hypertension, cardio/cerebrovascular disease and diabetes/diabetic complications.

Most of the patients were patients with ischemic stroke, males, retirees/unemployed, married, covered by the Urban Employees' Basic Medical Insurance and with admission route from an outpatient service. More than 93\% of subjects were collected from tertiary hospitals, especially from TCM hospitals with TCM treatment. The proportion of hospitals using clinical pathways was $69.6 \%$, but the proportion for patients was just $30.2 \%$. Most of the variables were statistically different between patients readmitted $\leq 31$ days and $>31$ days after discharge, except three variables (comorbidities with dyslipidemia or heart disease, and surgical treatment). (Table 1).

Among all the patients, the proportion of patients with hypertension was $5.32 \%$ in the $18-4.9$ age group, which was the lowest one among all the age groups. However, among those patients with hypertension, the proportion for patients readmitted $\leq 31$ days after discharge due to a stroke-related condition in the 18-49 age group was highest (38.7\%), compared to other age groups. The situations for diabetes, dyslipidemia, heart diseases were the same as hypertension. The proportions for patients readmitted $\leq 31$ days after discharge in the 18-49 age group were also highest among patients with the above three diseases, 36.9, 35.5 and 35.8\%, respectively. (Fig. 4).

The MLM analyses showed that patients with diabetes $(\mathrm{OR}=1.089, P=0.001)$, using clinical pathways $(\mathrm{OR}=$ 1.174, $P<0.001)$, and leaving or transferred without the doctor's advice $(\mathrm{OR}=1.485, P<0.001)$ had a higher risk of unplanned readmission $\leq 31$ days. Whereas, compared to patients with self-paying medical service, patients with basic medical insurances $(\mathrm{OR}=0.504, \mathrm{P}<0.001)$, urban resident basic medical insurance $(\mathrm{OR}=0.514, \mathrm{P}<0.001)$, new rural cooperative medical scheme $(\mathrm{OR}=0.643, \mathrm{P}<$ $0.001)$, medical financial assistance fund for the poor $(\mathrm{OR}=0.309, \mathrm{P}<0.001))$ and commercial medical insurance $(\mathrm{OR}=0.636, P=0.021)$ were at a lower risk. A lower risk was also observed in patients aged 50 years old and above (OR ranging from 0.650 to $0.985, P<0.05$ ), with haemorrhagic stroke $(\mathrm{OR}=0.467, \mathrm{P}<0.001)$, or if length of stay was more than 7 days in hospital (OR ranging from 0.082 to $0.566, \mathrm{P}<0.001$ ) (Table 2 ).

\section{Discussion}

This study comprehensively assessed the impact of both disease-related and unrelated factors on the risk of 31-day unplanned readmission after stroke, including social, financial, hospital or health system-related factors. We

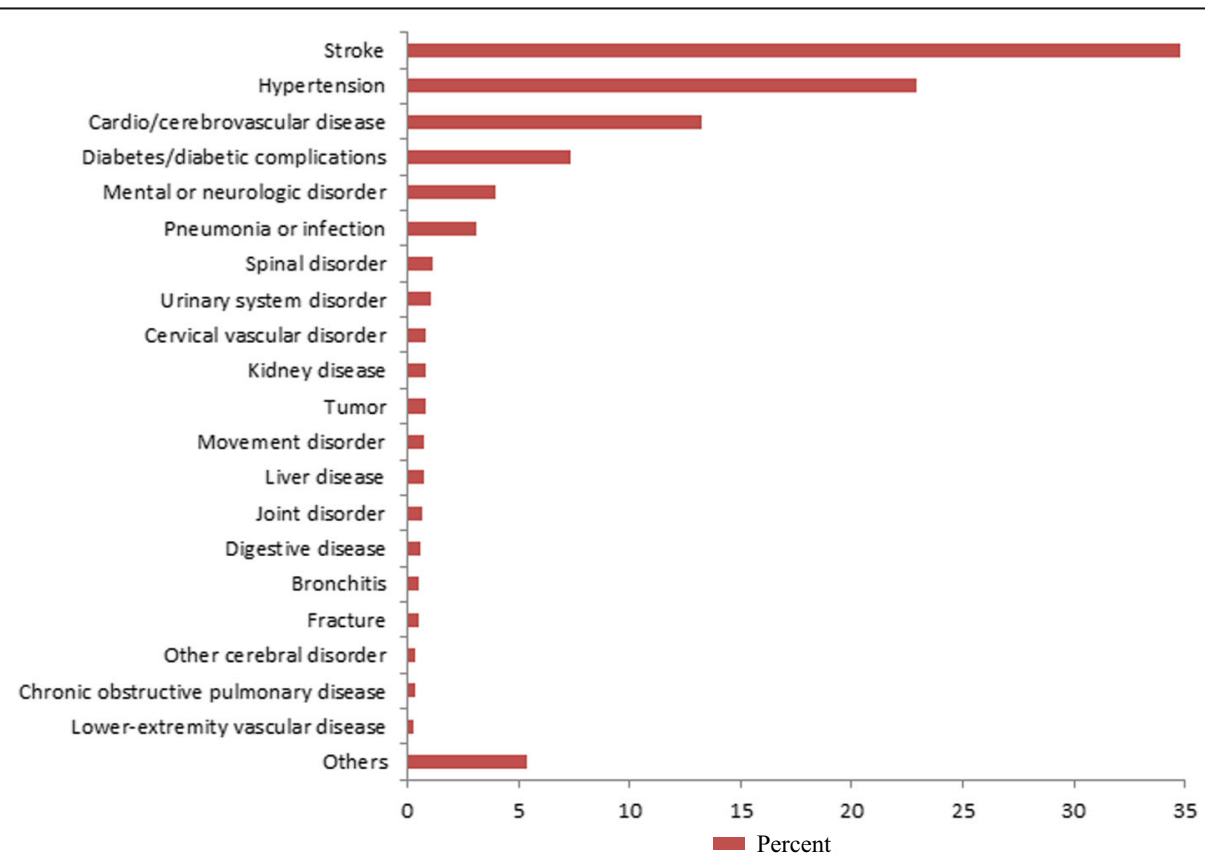

Fig. 3 Reasons for readmissions. Percent 
Table 1 Patient characteristics, comorbidities, health system and clinical process-related factors for the risk of hospital readmission $\leq 31$ days

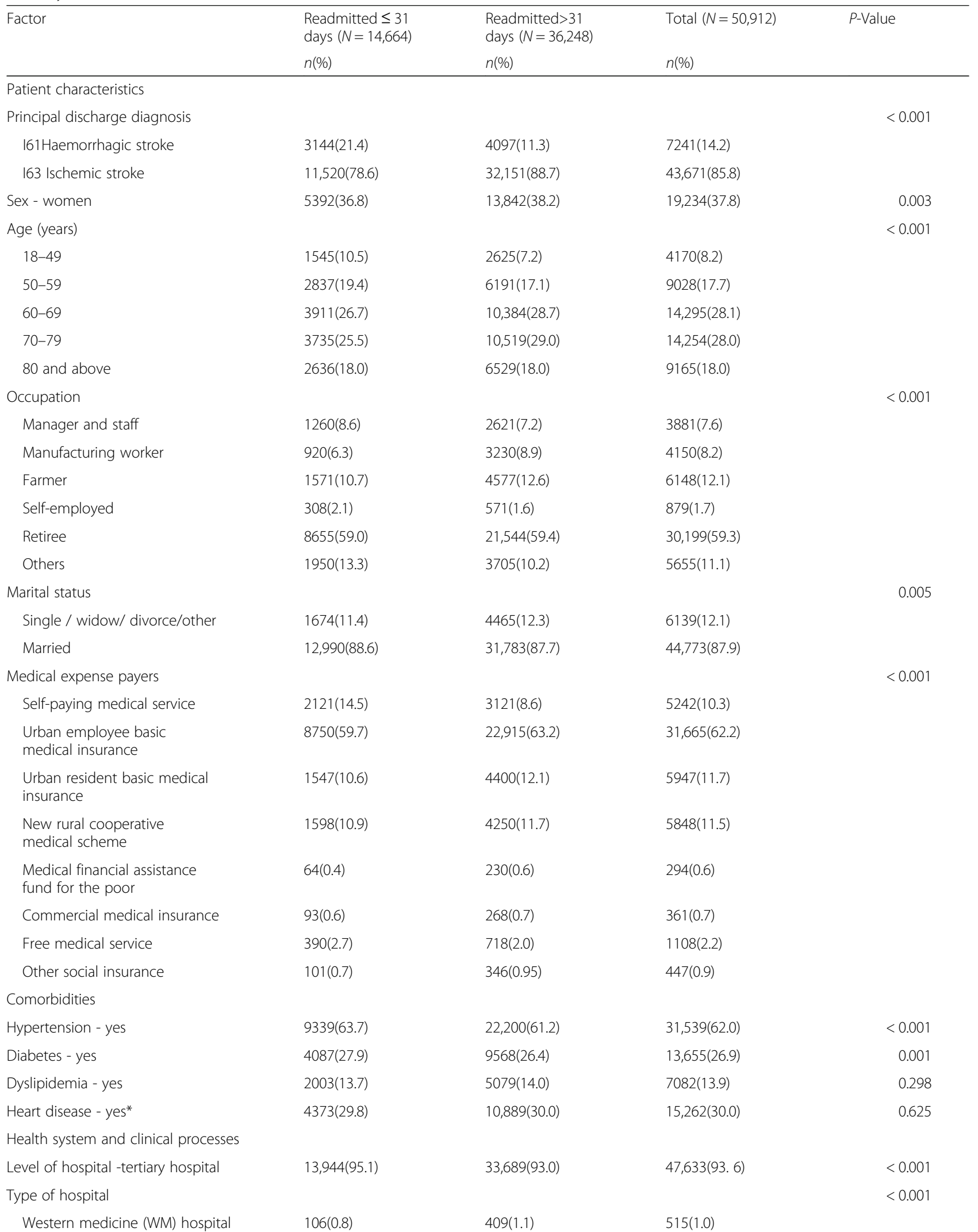


Table 1 Patient characteristics, comorbidities, health system and clinical process-related factors for the risk of hospital readmission $\leq 31$ days (Continued)

\begin{tabular}{|c|c|c|c|c|}
\hline \multirow[t]{2}{*}{ Factor } & $\begin{array}{l}\text { Readmitted } \leq 31 \\
\text { days }(N=14,664)\end{array}$ & $\begin{array}{l}\text { Readmitted }>31 \\
\text { days }(N=36,248)\end{array}$ & Total $(N=50,912)$ & \multirow[t]{2}{*}{$P$-Value } \\
\hline & $n(\%)$ & $n(\%)$ & $n(\%)$ & \\
\hline TCM hospital & $13,491(92.0)$ & $32,793(90.5)$ & $46,284(90.9)$ & \\
\hline TCM-WM hospital & $976(6.7)$ & $2826(7.8)$ & $3802(7.5)$ & \\
\hline Ethnic minority hospital & $91(0.6)$ & $220(0.6)$ & $311(0.6)$ & \\
\hline Admission route & & & & $<0.001$ \\
\hline Emergency & 4592(31.3) & $11,937(33.0)$ & $16,529(32.5)$ & \\
\hline Outpatient & $9541(65.1)$ & $22,420(61.9)$ & $31,961(62.8)$ & \\
\hline $\begin{array}{l}\text { Others (such as Transferred } \\
\text { from other hospitals) }\end{array}$ & $531(3.6)$ & $1891(5.2)$ & $2422(4.8)$ & \\
\hline Length of hospital stay (days) & & & & $<0.001$ \\
\hline $1-7$ & 2094(14.3) & $2531(7.0)$ & $4625(9.1)$ & \\
\hline $8-14$ & $5432(37.0)$ & $14,163(39.1)$ & $19,595(38.5)$ & \\
\hline $15-21$ & 4387(29.9) & $10,250(28.3)$ & $14,637(28.8)$ & \\
\hline $22-28$ & 1982(13.5) & $3699(10.2)$ & $5681(11.2)$ & \\
\hline 29 and above & $769(5.2)$ & $5605(15.5)$ & $6374(12.5)$ & \\
\hline Use of clinical pathways ${ }^{* *}$ - yes & 4707(32.1) & $10,664(29.4)$ & $15,371(30.2)$ & $<0.001$ \\
\hline Surgical treatment - yes & $705(4.8)$ & $1794(5.0)$ & 2499(4.9) & 0.503 \\
\hline Use TCM treatment - yes & $13,224(90.2)$ & $31,560(87.1)$ & $44,784(88.0)$ & $<0.001$ \\
\hline Type of discharge & & & & 0.033 \\
\hline $\begin{array}{l}\text { Leave or transfer with } \\
\text { doctor's advice }\end{array}$ & $14,100(96.2)$ & 34,994(96.5) & 49,094(96.4) & \\
\hline Others*** & $564(3.8)$ & $1254(3.5)$ & 1818(3.6) & \\
\hline
\end{tabular}

*Heart disease includes coronary heart disease, angina pectoris, arrhythmia, heart failure, atrial fibrillation, and myocardial infarction **In terms of hospitals, $69.6 \%$ of hospitals used clinical pathways

${ }^{* * *}$ Others include patients discharged without doctor's advice and those deceased

found that recurrent stroke was the most important reason for readmission. Age, type of stroke, medical expense payment, type of discharge, use of clinical pathways, length of hospital-stay and some comorbidities were the most influential factors for readmission within 31 days for a stroke related condition.

Patients aged younger than 50 years old had a higher readmission risk than older patients. It is probably because of large increases in the common stroke risk factors in that age group, such as tobacco use, hypertension, and diabetes mellitus [25-27]. In China, the 2010 Global Adults Tobacco Survey results showed that from 2002 to 2010, the male current smoking prevalence in the age group of $40-59$ increased dramatically by nearly $70 \%$, while current smoking prevalence among other age groups didn't change significantly [28]. The hypertension prevalence increased among adults aged 35 years old and above. According to China Kadoorie Biobank Study, compared with other age groups, the hypertension prevalence was $12.6 \%$ in the $35-39$ age group, also with a greater proportion of uncontrolled hypertension [29]. The prevalence of diabetes was 3.2 and $11.5 \%$ among persons aged 20-39 and $40-59$, respectively [30]. In the $18-39$ age group, the rate of diabetes awareness was extremely low (5\%), also with the lowest treatment and control rate among all the adults aged 18 years old and above [31]. Therefore, it is important to control these potential risk factors, especially for people aged under 50 years.

Patients with haemorrhagic stroke had a higher risk of readmission $\leq 31$ days perhaps because strokes are generally more severe in patients with haemorrhagic stroke. In one study conducted in Denmark, stroke severity was found to be correlated with the probability of having haemorrhagic stroke (2\% in patients with the mildest stroke and $30 \%$ in those with the most severe strokes) [32].

Use of clinical pathways was also found to be associated with readmission $\leq 31$ days. In order to improve professional practice and treatment outcome, as well as reduce length of stay and hospital cost, National Health Commission of China issued a Guideline for Clinical Pathways Management (pilot version) in 2009 [33], which requires different health organizations/hospitals at each level to make their own clinical pathways for common diseases. This guideline was updated in August 


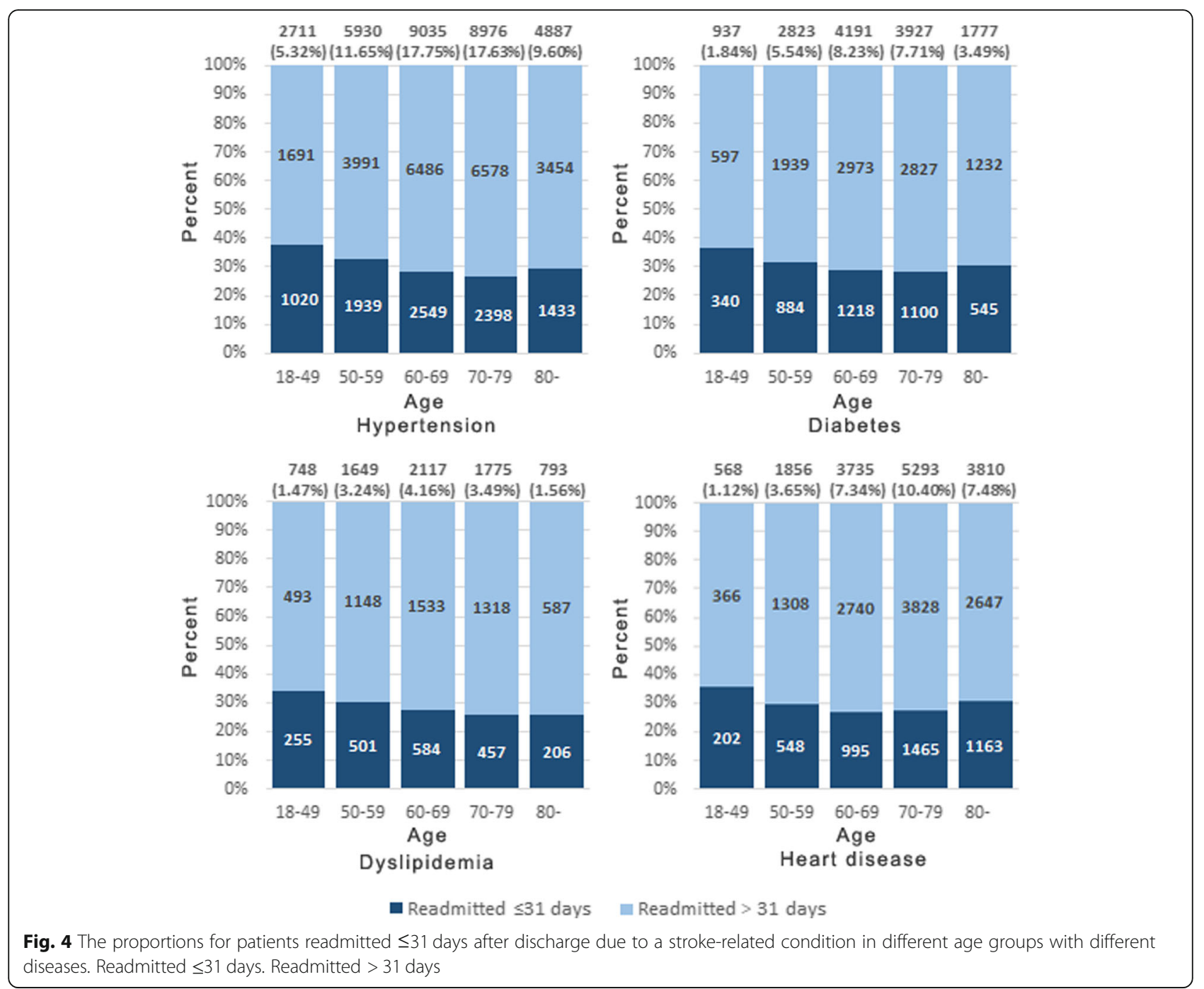

2017, which requires those patients with confirmed diagnosis, but without severe complications, could get clinical pathways. Once those patients under the clinical pathways have severe complications who have to be changed treatment strategy / clinical department, they should quit clinical pathways [34]. Since 2009, most hospitals have developed their clinical pathways for stroke. In our study, $69.6 \%$ of hospitals use clinical pathways. But the use of clinical pathways in stroke care is questionable, because the evidence on effectiveness is still inconclusive, not only in China [35], but also in other countries [36]. Thus, further research is needed before widespread implementation of these clinical pathways. However, it should be noted that in the univariable analysis, the prevalence of using clinical pathways in two groups (readmitted $\leq 31$ days and $>31$ days) was just $3 \%$ difference, which means that this significant difference may be associated with the large sample size and may not be clinically relevant.
Patients with more than 7 days of hospital stay had a lower risk for readmission within 1 month, compared to those with $\leq 7$ days of hospital stay. An Australian study showed that the median length of stay for readmission was 6 days $\left(\mathrm{Q}_{1}-\mathrm{Q}_{3}, 2-12\right)[10]$. This indicates that, at least for some stroke patients, 6-7 days of treatment in hospital may be inadequate; and for those patients in serious condition and less than 7 days of hospital stay, transitions to other healthcare services after discharge to prevent unplanned readmission should be considered [37].

Because the data for this study was obtained from the Monitoring Database of National Key TCM Project, there were some limitations in our study. Firstly, more than $91 \%$ of patients included in our analysis were from TCM hospitals. Hospitals in China are classified into western medicine (WM) hospitals and TCM hospitals. In almost every county and city, there is at least one TCM hospital. In 2013, there were 3105 TCM hospitals in China, accounting for $12.6 \%$ of all hospitals [38]. Our 
Table 2 Multilevel logistic regression, factors associated with readmission $\leq 31$ days $^{a}$

\begin{tabular}{|c|c|c|c|c|}
\hline \multirow[t]{2}{*}{ Factor } & \multirow[t]{2}{*}{ OR } & \multicolumn{2}{|l|}{$95 \% \mathrm{Cl}$} & \multirow[t]{2}{*}{$P$-Value } \\
\hline & & Lower & Upper & \\
\hline \multicolumn{5}{|l|}{ Patient characteristics } \\
\hline $\begin{array}{l}\text { Principal discharge diagnosis - } 161 \\
\text { Haemorrhagic stroke }\end{array}$ & 1 & & & \\
\hline I63 Ischemic stroke & 0.467 & 0.437 & 0.498 & $<0.001$ \\
\hline Sex - male & 1 & & & \\
\hline female & 0.995 & 0.950 & 1.042 & 0.842 \\
\hline Age (years) - 18-49 & 1 & & & \\
\hline $50-59$ & 0.820 & 0.749 & 0.898 & $<0.001$ \\
\hline $60-69$ & 0.737 & 0.662 & 0.819 & $<0.001$ \\
\hline $70-79$ & 0.725 & 0.650 & 0.808 & $<0.001$ \\
\hline 80 and above & 0.879 & 0.784 & 0.985 & 0.027 \\
\hline Occupation - Manager and staff & 1 & & & \\
\hline Manufacturing worker & 0.962 & 0.846 & 1.094 & 0.556 \\
\hline Farmer & 1.090 & 0.959 & 1.238 & 0.187 \\
\hline Self-employed & 0.958 & 0.785 & 1.169 & 0.674 \\
\hline Retiree & 1.092 & 0.984 & 1.212 & 0.099 \\
\hline Others & 1.072 & 0.961 & 1.195 & 0.211 \\
\hline $\begin{array}{l}\text { Marital status -Single / } \\
\text { widow/ divorce/other }\end{array}$ & 1 & & & \\
\hline Married & 0.969 & 0.898 & 1.046 & 0.422 \\
\hline $\begin{array}{l}\text { Medical expense payers - } \\
\text { Self-paying medical service }\end{array}$ & 1 & & & \\
\hline $\begin{array}{l}\text { Urban employee basic } \\
\text { medical insurance }\end{array}$ & 0.504 & 0.467 & 0.544 & $<0.001$ \\
\hline $\begin{array}{l}\text { Urban resident basic } \\
\text { medical insurance }\end{array}$ & 0.514 & 0.466 & 0.567 & $<0.001$ \\
\hline $\begin{array}{l}\text { New rural cooperative } \\
\text { medical scheme }\end{array}$ & 0.643 & 0.578 & 0.716 & $<0.001$ \\
\hline $\begin{array}{l}\text { Medical financial } \\
\text { assistance fund for the poor }\end{array}$ & 0.309 & 0.225 & 0.424 & $<0.001$ \\
\hline $\begin{array}{l}\text { Commercial medical } \\
\text { insurance }\end{array}$ & 0.636 & 0.433 & 0.934 & 0.021 \\
\hline Free medical service & 0.865 & 0.735 & 1.017 & 0.079 \\
\hline Other social insurance & 0.447 & 0.345 & 0.581 & $<0.001$ \\
\hline \multicolumn{5}{|l|}{ Comorbidities } \\
\hline Hypertension - no & 1 & & & \\
\hline yes & 0.966 & 0.918 & 1.017 & 0.188 \\
\hline Diabetes - no & 1 & & & \\
\hline yes & 1.089 & 1.035 & 1.145 & 0.001 \\
\hline \multicolumn{5}{|l|}{$\begin{array}{l}\text { Health system and clinical } \\
\text { processes }\end{array}$} \\
\hline $\begin{array}{l}\text { Rank of hospital -primary } \\
\text { and secondary hospital }\end{array}$ & 1 & & & \\
\hline tertiary hospital & 1.168 & 0.845 & 1.614 & 0.348 \\
\hline $\begin{array}{l}\text { Type of hospital - Western } \\
\text { medicine (WM) hospital }\end{array}$ & 1 & & & \\
\hline TCM hospital & 1.194 & 0.778 & 1.833 & 0.417 \\
\hline
\end{tabular}


Table 2 Multilevel logistic regression, factors associated with readmission $\leq 31$ days ${ }^{\text {a }}$ (Continued)

\begin{tabular}{|c|c|c|c|c|}
\hline \multirow[t]{2}{*}{ Factor } & \multirow[t]{2}{*}{ OR } & \multicolumn{2}{|l|}{$95 \% \mathrm{Cl}$} & \multirow[t]{2}{*}{$P$-Value } \\
\hline & & Lower & Upper & \\
\hline TCM-WM hospital & 1.287 & 0.768 & 2.156 & 0.339 \\
\hline Ethnic minority hospital & 1.360 & 0.564 & 3.279 & 0.493 \\
\hline Admission route - Emergency & 1 & & & \\
\hline Outpatient & 0.994 & 0.929 & 1.064 & 0.860 \\
\hline $\begin{array}{l}\text { Others (such as Transferred } \\
\text { from other hospitals) }\end{array}$ & 1.140 & 0.945 & 1.374 & 0.170 \\
\hline Length of hospital stay (days) - 1-7 & 1 & & & \\
\hline $8-14$ & 0.444 & 0.411 & 0.478 & $<0.001$ \\
\hline $15-21$ & 0.459 & 0.424 & 0.496 & $<0.001$ \\
\hline $22-28$ & 0.516 & 0.470 & 0.566 & $<0.001$ \\
\hline 29 and above & 0.092 & 0.082 & 0.103 & $<0.001$ \\
\hline Use of clinical pathways - no & 1 & & & \\
\hline yes & 1.174 & 1.108 & 1.243 & $<0.001$ \\
\hline Use TCM treatment - no & 1 & & & \\
\hline yes & 1.036 & 0.944 & 1.136 & 0.458 \\
\hline $\begin{array}{l}\text { Type of discharge - Leaving or } \\
\text { transferred with doctor's advice }\end{array}$ & 1 & & & \\
\hline Others* & 1.485 & 1.272 & 1.733 & $<0.001$ \\
\hline
\end{tabular}

*Others include patients discharged without doctor's advice and those deceased

${ }^{a}$ Random-effects variance:0.792; interclass correlation: 0.194 ; OR: odds ratio; Cl: confidence interval

current study included 375 hospitals, covering almost all provinces of China, which might be representative of all TCM hospitals. Nowadays, combined diagnosis and treatment of TCM and WM are the most common strategy used in TCM hospitals or clinics. In China, the basic treatment strategies in the TCM hospitals were the same as those in WM hospitals because all hospitals should follow the Guideline for Stroke Diagnosis and Treatment issued by Chinese Medical Association [39]. In addition, TCM hospitals or clinics should also comply with the Guideline for Stroke Diagnosis and Treatment by TCM issued by State Administration of TCM [40], which means that doctors may add some TCM treatment modalities, such as Chinese herb or acupuncture, depending on the severity of stroke patients. It is unknown whether or not this had an impact on our findings.

Secondly, because these data were secondary data from each inpatient's cover sheet of medical records and not designed for research purposes, some important medical information was not recorded. For example, data on the severity of stroke could not be extracted from the database. An Australian study reported that being dependent before the initial admission (modified Rankin Scale, 2-5) was significantly associated with readmission within 28 days [10]. Also, the clinical criteria for patient discharge could not be collected from the cover sheet of medical records. Thirdly, we were unable to track patients who did not come back to hospital; they may have fully recovered or they may have died.
Lastly, our study findings using multilevel logistic modeling may face a risk of bias. This is because the odds ratio (OR) is approximately the same as the relative risk (RR) if the outcome of interest is rare [41]. However, in our study the readmission rate was $28.8 \%$. Therefore, we had tried to use the multilevel log-binomial regression. Unfortunately, the results showed that the log-binomial model was inappropriate for our data which may be caused by an imbalance in the numbers of different types of hospitals. Hence, we reported the result of multilevel logistic regression in this article. These limitations may potentially cause some biases in our results. Generalizability to other countries may also be limited because most hospitals were TCM.

\section{Conclusions}

In summary, recurrent stroke, hypertension, cardio/cerebrovascular disease and diabetes/diabetic complications are the most common reasons for readmissions. Age, type of stroke, medical expense payment, type of discharge, use of clinical pathways, length of hospital-stay and some comorbidities were the most influential factors for readmission within 31 days. Interventions aimed at preventing 31-day readmissions should place more attention to patients with comorbidities, or unhealthy behaviors, especially for young and middle-aged patients. Further research is needed before widespread implementation of the clinical pathways for stroke. Hospitals should consider whether patients with $\leq 7$ days of hospital stay may benefit from staying longer. 


\section{Abbreviations}

Cl: Confidence interval; MLM: Multilevel logistic modeling; OR: Odds ratio; RR: Risk ratio; TCM: Traditional Chinese Medicine; WM: Western medicine

\section{Acknowledgments}

The authors thank the Monitoring Program of National Key TCM Project for their support in providing the data set for this study.

\section{Funding}

The research described was supported by the Beijing Administration of TCM (Grant No. JJ2016-83) and the Fundamental Research Funds for the Central Public Welfare Research Institutes (Grant No. Z0477). The former grant supported the design, data collection and analysis of this study, and the latter one supported the interpretation of data and in writing the manuscript.

\section{Availability of data and materials}

The data that support the findings of this study are available from Monitoring Database of National Key Traditional Chinese Medicine Project, which is managed by Data Center of Traditional Chinese Medicine at China Academy of Chinese Medical Sciences. The dataset used and analyzed in this study is available from the corresponding author upon reasonable request. The raw data of this project is not publicly available under the national regulation: Administrative Measures for the Graded Protection of Information Security (No.43 [2007]). However, data are available from the authors upon reasonable request and with permission of Data Center of Traditional Chinese Medicine at China Academy of Chinese Medical Sciences.

\section{Authors' contributions}

TCW interpreted the findings and was a major contributor in writing the manuscript. BYL and YNZ were involved in the design and coordination of the study and revision of the manuscript. XW and AYL were involved in interpretation of the results and revision of the manuscript. XPZ contributed to the model development and data analysis. JZ cleaned the data and contributed to the interpretation of the results. $X Z Z$ reviewed the model and contributed to the analysis. All authors read and approved the final manuscript.

\section{Ethics approval and consent to participate}

The ethics committees at Institute of Basic Research in Clinical Medicine at China Academy of Chinese Medical Sciences approved this study (Reference number: 2016NO.11-01) on November 7, 2016. The China Academy of Chinese Medical Sciences granted administrative permission to access the raw data from the Medical Record Monitoring Database.

\section{Consent for publication}

Not applicable.

\section{Competing interests}

The authors declare that they have no competing interests.

\section{Publisher's Note}

Springer Nature remains neutral with regard to jurisdictional claims in published maps and institutional affiliations.

\footnotetext{
Author details

'School of Computer Science, Northwestern Polytechnical University Xi'an, Shangxi Province 710129, China. ${ }^{2}$ Institute of Basic Research in Clinical Medicine, China Academy of Chinese Medical Sciences, Beijing 100700, China. ${ }^{3}$ Data Center of Traditional Chinese Medicine, China Academy of Chinese Medical Sciences, Beijing 100700, China. ${ }^{4}$ Institute of Basic Medical Sciences at Chinese Academy of Medical Sciences / School of Basic Medicine at Peking Union Medical College, Beijing 100005, China. ${ }^{5}$ School of Computer and Information Technology, Beijing Jiaotong University, Beijing 100044, China. ${ }^{6}$ Faculty of Medicine, The Chinese University of Hong Kong, Hong Kong, China.
}

Received: 23 January 2018 Accepted: 29 November 2018

Published online: 26 December 2018

\section{References}

1. Yang GH, Wang Y, Zeng YX, Gao FG, Liang XF, Zhou MG, et al. Rapid health transition in China, 1990-2010: findings from the global burden of disease study 2010. Lancet. 2013;381:1987-2015.

2. Chen WW, Gao RL, Liu LS, Zhu ML, Wang W, Wang YJ, et al. Synopsis of the report on cardiovascular diseases in China (2017). Chin Circulation J. 2018; 33(1):1-8

3. Information Office of Ministry of Health of China. Report on the third National Survey of death causes. China Cancer. 2008;17(5):344-5.

4. Ma Y, Xiong XJ, Li JH, Fang YY. Effect of health insurance on direct hospitalization costs for in-patients with ischemic stroke in China. Aust Health Rev. 2017. https://doi.org/10.1071/AH16056.

5. National Health and Family Planning Commission of China. China health and family planning statistics yearbook. Peking Union Medical College Press. 2016;2016:p113

6. Liu J, Yang D, Li XR, Zhou SJ. Status of readmission $\leq 31$ days and influencing factors analysis in one hospital. Chinese Health Quality Management. 2011;18(6):22-5.

7. Thomas JW, Holloway JJ. Investigating early readmission as an indicator for quality of care studies. Med Care. 1991;29(4):377-94.

8. General Office, Ministry of Health. Ministry of Health issued and published medical quality management and control indicators for tertiary general hospitals. http://www.gov.cn/gzdt/2011-01/27/content_1793358.htm. Accessed 23 Apr 2018.

9. Bhattacharya P, Khanal D, Madhavan R, Chaturvedi S. Why do ischemic stroke and transient ischemic attack patients get readmitted? J Neurol Sci. 2011:307(1-2):50-4.

10. Kilkenny MF, Longworth M, Pollack M, Levi C, Cadilhac DA. Factors associated with 28-day hospital readmission after stroke in Australia. Stroke. 2013:44(8):2260-8

11. Lichtman JH, Leifheit-Limson EC, Jones SB, Wang Y, Goldstein BL. Preventable readmissions within 30 days of ischemic stroke among Medicare beneficiaries. Stroke. 2013;44(12):3429-35.

12. Kind AJ, Smith MA, Liou JI, Pandhi N, Frytak JR, Finch MD. The price of bouncing back: one-year mortality and payments for acute stroke patients with 30-day bounce-backs. J Am Geriatr Soc. 2008;56:999-1005.

13. Nouh AM, McCormick L, Modak J, Fortunato G, Staff I. High mortality among 30-day readmission after stroke: predictors and etiologies of readmission. Front Neurol. 2017;8:632. https://doi.org/10.3389/fneur. 2017.00632

14. Liotta EM, Singh M, Kosteva AR, Beaumont JL, Guth JC, Bauer RM, et al. Predictors of 30 day readmission after intracerebral hemorrhage: a singlecenter approach for identifying potentially modifiable association with readmission. Crit Care Med. 2013;41(12):1-14.

15. Rao A, Emily B, Sabine V, Darzi A, Aylin P. Systematic review of hospital readmissions in stroke patients. Stroke Res Treat. 2016;2016(1):1-11.

16. Lewsey J, Ebueku O, Jhund PS, Gillies M, Chalmers WTJ, Redpath A, et al. Temporal trends and risk factors for readmission for infections, gastrointestinal and immobility complications after an incident hospitalization for stroke in Scotland between 1997 and 2005. BMC Neurol. 2015;15:3. https://doi.org/10.1186/s12883-014-0257-1.

17. Tseng MC, Lin HJ. Readmission after hospitalization for stroke in Taiwan: results from a national sample. J Neurol Sci. 2009;284(1-2):52-5.

18. Bureau of Medical Administration, National Health and Family Planning Commission of China. Filling standards of cover sheet data of medical records (interim). May 31, 2016. http://www.nhfpc.gov.cn/yzygj/s2909/ 201606/fa8a993ec972456097a2a47379276f03.shtml. Accessed 27 Nov 2017.

19. General Office, State Administration of Traditional Chinese Medicine of the People's Republic of China. Filling standards of cover sheet data of medical records in TCM hospitals (interim). 2017.

20. Caro JJ, Migliacciowalle K, Ishak KJ, Proskorovsky I, O'Brien JA. The time course of subsequent hospitalizations and associated costs in survivors of an ischemic stroke in Canada. BMC Health Serv Res. 2006:6(1):99.

21. Resolution of the Standing Committee of the National People's Congress. Interim Measures of the State Council on Settlement of Cadres Who Are Old, Weak, Sick or disabled. 1978

22. O'Donnell MJ, Chin SL, Rangarajan S, Xavier D, Liu L, Zhang H, et al. Globa and regional effects of potentially modifiable risk factors associated with 
acute stroke in 32 countries (INTERSTROKE): a case-control study. Lancet. 2016;388(10046):761-75.

23. Burke JF, Skolarus LE, Adelman EE, Reeves MJ, Brown DL. Influence of hospital-level practices on readmission after ischemic stroke. Neurology. 2014;82(24):2196-204.

24. Li F, Yang L, Yang R, Xu W, Chen FP, Li N, et al. Ischemic stroke in young adults of northern China: characteristics and risk factors for recurrence. Eur Neurol. 2017;77:115-22.

25. Singhal $A B$, Biller J, Elkind MS, Fullerton HJ, Jauch EC, Kittner SJ, Levine DA, Levine SR. Recognition and management of stroke in young adults and adolescents. Neurology. 2013;81:1089-97.

26. Dževdet S. Strokes in young adults: epidemiology and prevention. Vasc Health Risk Manag. 2015;11:157-64.

27. Renna R, Pilato F, Profice P, Della Marca G, Broccolini A, Morosetti R, et al. Risk factor and etiology analysis of ischemic stroke in young adult patients. J Stroke Cerebrovasc Dis. 2014;23(3):e221-7.

28. Yang GH, editor. China Adult Tobacco Survey in 2010. China: Beijing: SanXia publishing house; 2011.

29. Lewington S, Lacey B, Clarke R, Guo Y, Kong XL, Yang L, et al. The burden of hypertension and associated risk for cardiovascular mortality in China. JAMA Intern Med. 2016;176(4):524-32.

30. Yang W, Liu J, Weng J, Jia W, Ji L, Xiao J, et al. Prevalence of diabetes among men and women in China. N Engl J Med. 2010;362:1090-101.

31. Qin YC, Wang R, Ma XQ, Zhao YF, Lu J, Wu C, et al. Prevalence, awareness, treatment and control of diabetes mellitus - a population based study in Shanghai, China. Int J Environ Res Public Health. 2016;13:512.

32. Andersen KK, Olsen TS, Dehlendorff C, Kammersgaard LP. Hemorrhagic and ischemic strokes compared. Stroke. 2009:40:2068-72.

33. Department of Medical Administration, National Health and Family Planning Commission of China. Clinical pathways in neurology. People's medical publishing house. 2012.p5-p8.

34. Department of Medical Administration, National Health and Family Planning Commission of China. The guidelines of clinical pathways management in medical institutions. http://www.nhfpc.gov.cn/ewebeditor/uploadfile/2017/ 09/20170912142358434.docx. Accessed 14 May 2018

35. Shi XF, Dai DM, Fan ST, Guo Y. The application status of clinical pathways for stroke patients. Chin J Integr Med. 2013:11(5):608-9.

36. Vanhaecht K, Ovretveit J, Elliott MJ, Sermeus W, Ellershaw JE, Panella M. Have we drawn the wrong conclusions about the value of care pathways? Is a Cochrane review appropriate? Eval Health Prof. 2012;35(1):28-42.

37. Lee HC, Chang KC, Lan CF, Hong CT, Huang YC, Chang ML. Factors associated with prolonged hospital stay for acute stroke in Taiwan. Acta Neurol Taiwanica. 2008;17:17-25.

38. National Health Commission of China. The report on annual National Health Statistics (2014). In: Peking union medical college press; 2014.

39. Chinese Medical Association. Clinical Pathways of Ischemic Stroke http://www.cma.org.cn/attachment/2016612/1465718140116.docx. Accessed 9 Jan 2018

40. General Office, State administration of traditional Chinese medicine of the People's Republic of China. Notice on clinical pathways, diagnosis and treatment scheme of Traditional Chinese Medicine for 92 diseases Mar 13, 2017 http://www.satcm.gov.cn/yizhengsi/gongzuodongtai/2018-03-24/2651. html. Accessed 27 May 2018.

41. Davies HTO, Crombie IK, Tavakoli M. When can odds ratios mislead? BMJ. 1998;316(7136):989-91.

Ready to submit your research? Choose BMC and benefit from:

- fast, convenient online submission

- thorough peer review by experienced researchers in your field

- rapid publication on acceptance

- support for research data, including large and complex data types

- gold Open Access which fosters wider collaboration and increased citations

- maximum visibility for your research: over $100 \mathrm{M}$ website views per year

At BMC, research is always in progress.

Learn more biomedcentral.com/submissions 